\title{
The Research of Automobile Production Line Management System Based on Industrial Engineering
}

\author{
-Application of RFID Technology in Automobile Production Line \\ Jiahui Liu and Guangqiu Lu \\ ${ }^{1}$ Qingdao Binhai University,West Jialingjiang Road, Development Zone of Qingdao,Qingdao, China \\ a1193121893@qq.com, b156360093@qq.com
}

Keywords: industrial engineering; RFID; automobile production line; Internet of things; management information systems

\begin{abstract}
With the rapid development of the automotive industry, cars have become the necessary means of transport. Because the automotive production process is complex, multi-species, multiparts, high quality requirements, the production line management system research is highly necessary. Enterprises through the establishment of a set of object-based product traceability information system can not only real-time grasp the actual situation of the production site, but also master the product quality problems, the rapid detection of problems related products, sources and impact of customers. For the production site found problems, you can timely adjust the production plan and switch raw materials to avoid duplication of defective products and resulting in greater losses. Based on the analysis of the system requirements, this paper builds a system based on the three-tier structure of the Internet of Things, and builds an automobile production line management system based on RFID technology.
\end{abstract}

\section{Introduction}

\section{Background and Significance of Research}

The global market, the emergence of food safety incidents, product recall events reflect the quality of products related to consumer safety and vital interests had to cause widespread concern. Both the manufacturer and the consumer want to know the content of the final product or consumer's raw material and source, the reliability of the product, the safety and the quality of the product. The purpose of this project is to realize the real-time query of product, product and customer in the supply chain and the product information in the environment of the Internet of Things.[1] Through the product traceability information system for producers and products to achieve the product quality of accurate, fast and complete tracking and traceability. Through the establishment of a fast and effective product-based product traceability information system can not only real-time grasp the actual situation of the production site, but also in the product quality problems, the rapid detection of problems related products, sources and impact client.

\section{Research status at home and abroad}

In the United States, for example, the establishment of the United States traceability system mainly follows the principle of voluntary, government-oriented, product traceability of the current domestic there is no uniform coding rules, the majority of product code by the system developers in the retrospective product object classification, In accordance with the principle of product coding uniqueness on the basis of custom rules in accordance with the product code. China started in the retrospective system construction started later in November 2010 held in Beijing, the Internet of things and product quality traceability forum, the forum mainly around the development of things, product quality and traceability of relevant technical standards and industry applications and other topics, a comprehensive Analysis and in-depth discussion for product research and application of the introduction of a new idea. From the overall development trend analysis, China's traceable system construction is still in the early stages of development, many traceability technology is only 
a small range of experimental applications need in-depth research and continuous improvement, therefore, China's product traceability technology research and traceability The development and application of the system there is still a lot of room for development.[3]

\section{The Research Content of This Topic}

The auto parts production enterprises as the research subject, in the production of enterprises as the core to establish traceability information system is an effective, low cost product quality, through the system to a range of problems down to a specific link of production and circulation of even specific operating personnel, so there is no need to find the source in the whole production chain in the narrow range, for improved efficiency. In addition, we can also accurately find the source of the quality of products and mitigate the negative economic impact of unrelated issues.

\section{RFID Summary}

\section{RFID Definition}

RFID is the abbreviation of radio frequency identification (RFID), which is a technique that automatically identifies the object and obtains the information carried by a radio frequency signal transmitted by a reader. It belongs to non-contact automatic identification technology, which can quickly identify objects and read and write information. A RFID by the general reader and can be attached to the object identifier of the RFID tags (RFID.[5] its principle is to use the electromagnetic principle fit through RF signal sending information stored in the RFID tag to the reader. Unlike bar code, which collects bar code information automatically, RFID can collect information of identification objects passively. Compared with other automatic identification technologies such as biometrics, bar code, magnetic card, IC card, RFID with non-contact readwrite, small mechanical wear, the reading distance is adjustable (from a few centimeters to several meters), long service life, high speed moving object fast recognition, strong environmental adaptability, easy operation and multiple tags at the same time recognition and many other technical characteristics.[6] therefore, is widely used in the transformation of information technology and automation control in the enterprise, has become the majority of enterprises in the application of automatic identification technology in the technology of choice.[7]

\section{RFID constitution}

Typical RFID system typically consists of three parts: the radio frequency tag (Tag), the reader and the computer system.[8]

RFID tag

The RFID tag is composed of RF coupling element and memory chips, each label is the only global electronic encoding (Unique Identifier, abbreviated as UID), the encoding is firing system data in ROM chip can not be tampered with. The user data area can be read, write, and overwritten, so that the RFID tag can be attached to the surface of the object to identify and record information about the target object. It can be divided into data carrier with simple storage function and programmable microprocessor data carrier. The data carrier of simple storage function, the function of realizing addressing and security logic is to use state machine on chip, and the data carrier of programmable processor replaces the state machine in RFID tag with microprocessor.

reader

The reader has the ability to read and write data. The operation of the RFID tag is divided into the global unique sequence number of the read RFID, the read and write user data (usually the identification information of the items). As a data acquisition terminal, it is not directly connected with the computer system, but through middle ware for data exchange. The basic function of the reader is to transmit data through the antenna and electronic tag, and read and write the tag data. In addition, the reader can also complete complex functions such as information control, multi label anti-collision, tag checking, the electronic tag will be stored identity object identification information will be stored in some additional information such as check information, etc.. A typical reader includes a radio frequency module (receiver and transmitter), an interface unit, a control unit, and a reader antenna. At present, many RFID readers add some additional interfaces, such as network interface, USB interface, sensor interface and so on, providing a variety of data 
transmission methods to facilitate access to computer systems[9].

\section{Computer System}

The computer system mainly completes the processing, storage and management of the tag information, and reads and writes the reader. It is the core of the data processing in the RFID system. According to the data transmitted by the RFID reader, or transfer the information to other modules of the system for the next step, if it is a complex system, it also has authentication, encryption and decryption. At present, each manufacturer's RFID product standards are not uniform, so different types of products have different data interfaces. In addition, each vendor also provides a set of software tools or interface functions that can be used for system development for a particular RFID product[10].

\section{The Working Principle of RFID System}

The working principle of RFID system is: passive tags (Passive Tag, passive tags or passive tags) working principle is that when the electronic tag into the effective recognition range of the reader, by receiving the read write device to send a certain frequency electromagnetic wave electromagnetic induction current to obtain energy and stored in the memory to send information reader. And the active tag (Active Tag, active tag or active label) works by that the tag sends out the signal of a certain frequency automatically after entering the valid reading distance. After receiving the information, the reader decodes and transfers the information to the computer system, and the computer system completes the judgment of the legitimacy of the tag, processes the data and makes corresponding control operations. From the information transfer between reader and reader and the way of energy sensing, the energy sensing of active and passive tags can be divided into backward scattering coupling and inductive coupling.[11]

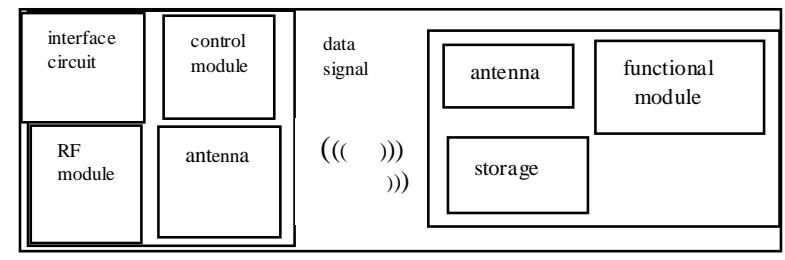

Figure 1. Working principle diagram of passive tag

\section{System Construction}

\section{Current Automotive Production Line Using Technology and Existing Problems}

At present, the main use of the production line many automobile enterprises is bar code technology, but the codes during the production can be damaged or fall off, the staff take the manual input code (Vehicle Identification Number VIN vehicle vehicle identification code) or parts of bar code, exist certain error rate; and the station staff take manual scanning body VIN bar code code or parts assembly information acquisition and vehicle tracking, the whole process takes a relatively large. The bar code data capacity can be stored from 2 to 3000 words.[12]

The amount of information that can be stored is limited. RFID technology can solve the above problems. In terms of scanning recognition, RFID technology is more accurate, penetrating and barrier free reading and writing, and highly resistant to water, oil, chemicals and other substances. The RFID tag is there will be chip data, so it can be against fouling. The content of the tag can be changed dynamically, and multiple tags can be processed simultaneously; the data access of the tag has password protection, and the security is higher; the maximum capacity of the RFID is several Mega Bytes, and the mass information can be stored. Auto production line management system based on RFID technology, will realize the information acquisition automatically, efficiently and accurately, the operator real-time remote control in the production line, so as to improve the product line qualification rate and reduce the labor intensity of the operator.[13]

\section{The Overall Framework of the System}

Things have different properties, applications in different industries such as intelligent transportation of things different from the logistics supply chain of IOT, all hardware and software is not the same, but there are three stages of common design things, thinking is based on the three layer, 
the perception layer, network layer (high speed data network), application layer (Internet), as shown in Figure 2:

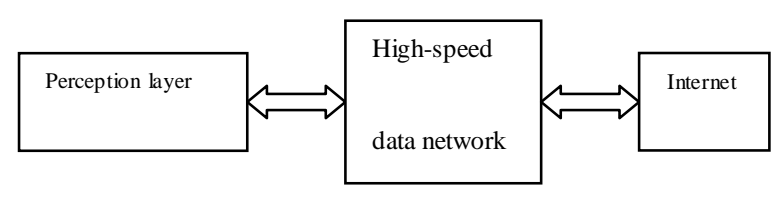

Figure 2. structure diagram of Internet of things

The automobile production line management system is also carried out according to the three layer structure of Internet of things. The overall architecture of the system is shown in figure 3:

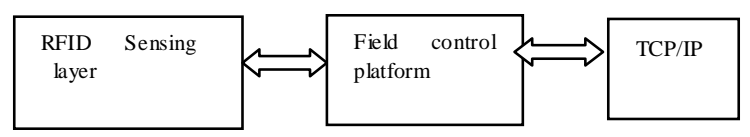

Figure 3. System framework

Perceptionlayer scheme is RFID in the sensing layer, is responsible for the real-time acquisition of information; network layer is responsible for site management and control platform, data communication between the sensing layer and the application layer; application layer of the Internet of things is a Web service, responsible for processing the collected data and presents data to the user interface.

\section{Three Story Structure Design}

\section{Design of RFID Sensing Layer}

In the vehicle or parts on the front line, the staff body scanning VIN codes, RFID vehicle tags initialization of the mounting surface on the front hood; high frequency hand held RFID reader VIN code information into the RFID label; the follow-up stations install the fixed frequency RFID reader. When the vehicle or parts after installation of the reader's position, the reader reads the tag information, and through WIFI (Wireless Fidelity, wireless compatibility certification, commonly known as wireless broadband) wireless transmission technology information data to the site management and control platform, the platform will be the corresponding control command information to the reader, the reader will write information label. As a result, through reading and writing RFID tags to complete the production line vehicle monitoring and data collection work, the reader realizes the data transmission between the RFID tag and the field management platform through WIFI technology. The selection of equipment and transmission technology for RFID sensing layer is shown in Table 1 and table 2:

Table 1 Equipment selection

\begin{tabular}{|l|l|}
\hline \multicolumn{1}{|c|}{$\begin{array}{c}\text { Device } \\
\text { name }\end{array}$} & \multicolumn{1}{|c|}{ Selection reasons } \\
\hline $\begin{array}{l}\text { High } \\
\text { frequency } \\
\text { handheld } \\
\text { RFID reader }\end{array}$ & $\begin{array}{l}\text { It integrates the functions of image } \\
\text { acquisition, wireless communication, bar } \\
\text { code scanning, RFID reader and so on. It } \\
\text { can meet the needs of mobile workers both } \\
\text { inside and outside the production line. It } \\
\text { can be used more efficiently and }\end{array}$ \\
\hline $\begin{array}{l}\text { Fixed-high } \\
\text { frequency } \\
\text { RFID reader }\end{array}$ & $\begin{array}{l}\text { Read and write excellent performance, } \\
\text { support intensive reading mode, built-in } \\
\text { WiFi }\end{array}$ \\
\hline $\begin{array}{l}\text { RFID } \\
\text { vehicle Tags }\end{array}$ & $\begin{array}{l}\text { Rewritable, has excellent reading } \\
\text { performance }\end{array}$ \\
\hline
\end{tabular}


Table 2 transmission selection

\begin{tabular}{|l|l|}
\hline \multicolumn{1}{|c|}{ Device name } & \multicolumn{1}{|c|}{ Selection reasons } \\
\hline \multirow{3}{*}{ WIFI } & $\begin{array}{l}\text { WIFI is a short-range wireless } \\
\text { technology suitable for indoor use. } \\
\text { It can cover up to 90 meters and } \\
\text { can cnmnletelv cnver the }\end{array}$ \\
\hline
\end{tabular}

\section{Web Service Design}

The establishment of ASP or JSP interface, the system received data from the TCP/IP network interface to the system managers, managers to do the appropriate operation, the data, control instructions transmitted to the field control platform. The key to Web service design is to obtain data from the TCP / IP network interface, and write the core classes of the TCP/IP port program using the Winsock API (Application Programming Interface application interface) function as follows:

\section{Receive data class:}

int CMySocket: : Receive( char* strData, int iLen ) / / Data receive function; \{

if $($ strData $==$ NULL $)$

return ERR_BADPARAM;

int len $=0$;

int ret $=0$;

ret $=\operatorname{recv}\left(\mathrm{m} \_\right.$hSocket, strData, iLen, 0$)$;

if $($ ret $==$ SOCKET_ERROR $)$

\{set_LastError( "recv( ) failed", WSAGetLastError( ) );

return ERR_WSAERROR;

return ret; \};

int CMySocket: : Send( char*

strData, int iLen ) / / Data transmission function; \{

if $(\operatorname{strData}==$ NULL $\|$ iLen $==0)$

return ERR_BADPARAM;

if $\left(\right.$ send $\left(\mathrm{m}_{-}\right.$hSocket, strData, iLen, 0$)==$ SOCKET

ERROR )

\{set_LastError( "send( ) failed", WSAGetLastError( ) );

return ERR_WSAERROR;

\}

return ERR_SUCCESS;

\}

When the communication connection is closed, the socket function is turned off:int shutdown( SOCKET s, int how );

int closesocket( SOCKET s);

\section{System Operation Process}

The RFID sensor layer real-time information collection production line, the information collected through the WIFI wireless transmission to the site management and control platform, control platform of the RFID site directly from the sensor layer data processing instructions, or through the mobile communication network TCP/IP network interface information transmission to the Web server and request instructions, system administrators will receive the data information make the corresponding treatment after the data or instructions on site management and control platform, then the platform site control command issued by the RFID sensor layer.

\section{System Simulation}

After the simulation, the application of auto production line RFID management system to achieve the production data accurate and real-time acquisition; at the same time to realize real-time monitoring of the work of production line; after using RFID production efficiency were significantly higher than in the production line management system using bar code technology, can improve the operational efficiency of the company's production. 


\section{Conclusion}

According to the characteristics of management system of automobile production line, RFID networking technology applied in automobile production line, the layered design of automobile production line management system based on RFID network technology, the enterprise can timely and accurate grasp of the production line, improve production efficiency, to provide accurate data to guarantee product quality tracking, and more to improve the automation and information of enterprise.

\section{References}

[1] Zhang Degan networking support technology[M]. Beijing: Science Press, 2014.

[2] $\mathrm{Wu}$ Xinhua, Lu Liping. Technology of Internet of things [M]. Beijing: Tsinghua University press, 2011.

[3] Liu heyao. Principle of Internet of things and its application technology [M]. Beijing: China Machine Press, 2011.

[4] Zhao Yanfeng, through the car manufacturers production logistics "Ren Du two pulse", [J]. cars and accessories. 2015 (37)

[5] Wanli, Ma Fei. RFID inventory management research on the application of [N]. Technology Innovation Herald of tobacco products in 2013 (22) .

[6] Yang Bifeng, Zhan Yanjun. Intelligent vehicle management system design of [J]. computer measurement and control based on radio frequency identification 2014(01) .

[7] Cheng Shaoshuai, research on the improvement of production logistics management system of X company's assembly workshop based on RFID technology, [D], 2015.

[8]Yang Jiandong, Wang $\mathrm{Pu}$, research on quality traceability management system based on RFID technology, [D], control engineering, 2015.

[9] Zhang Minghu, design and implementation of product line management system based on RFID technology, [J], automation and instrumentation, 2015.

[10] Ren Juanjuan, supply chain management information system design based on RFID technology, [J], automation and instrumentation, 2015.

[11] Chong Y Lee. A Recent Development of the Integrated Manufacturing System: A Hybrid of MRP and JIT[J], International Journal of operations \& Production Management, 2013, 13(4):3-17.

[12] T J Hodgson, Dinwei Wang. Optimal Hybrid Push/pull Control Strategies for a Parallel Multistage System: Part 1 h[J], Int. J. Production Research, 1991:29(6):1279-1287.

[13] David L. Brock, "Integrating the Electronic Product Code (EPC) and the Global Trade Item Number (GTIN)"Auto-ID White Paper [J] , WH-004, Distribution restricted to sponsor until February, 2012. 